\title{
Evidence for low-energy ions influencing plasma-assisted atomic layer deposition of SiO2: Impact on the growth per cycle and wet etch rate
}

\author{
Citation for published version (APA): \\ Arts, K., Deijkers, J. H., Faraz, T., Puurunen, R. L., Kessels, W. M. M., \& Knoops, H. C. M. (2020). Evidence for \\ low-energy ions influencing plasma-assisted atomic layer deposition of SiO2: Impact on the growth per cycle and \\ wet etch rate. Applied Physics Letters, 117(3), [031602]. https://doi.org/10.1063/5.0015379
}

\section{Document license: \\ TAVERNE}

DOI:

$10.1063 / 5.0015379$

Document status and date:

Published: 20/07/2020

\section{Document Version:}

Publisher's PDF, also known as Version of Record (includes final page, issue and volume numbers)

\section{Please check the document version of this publication:}

- A submitted manuscript is the version of the article upon submission and before peer-review. There can be important differences between the submitted version and the official published version of record. People interested in the research are advised to contact the author for the final version of the publication, or visit the $\mathrm{DOI}$ to the publisher's website.

- The final author version and the galley proof are versions of the publication after peer review.

- The final published version features the final layout of the paper including the volume, issue and page numbers.

Link to publication

\footnotetext{
General rights

- You may freely distribute the URL identifying the publication in the public portal. follow below link for the End User Agreement:

www.tue.nl/taverne

\section{Take down policy}

If you believe that this document breaches copyright please contact us at:

openaccess@tue.nl

providing details and we will investigate your claim.
}

Copyright and moral rights for the publications made accessible in the public portal are retained by the authors and/or other copyright owners and it is a condition of accessing publications that users recognise and abide by the legal requirements associated with these rights.

- Users may download and print one copy of any publication from the public portal for the purpose of private study or research.

- You may not further distribute the material or use it for any profit-making activity or commercial gain

If the publication is distributed under the terms of Article $25 \mathrm{fa}$ of the Dutch Copyright Act, indicated by the "Taverne" license above, please 


\section{Evidence for low-energy ions influencing plasma-assisted atomic layer deposition of $\mathrm{SiO}_{2}$ : Impact on the growth per cycle and wet etch rate ${ }^{\circledR}$}

Cite as: Appl. Phys. Lett. 117, 031602 (2020); https://doi.org/10.1063/5.0015379

Submitted: 27 May 2020 . Accepted: 08 July 2020 . Published Online: 22 July 2020

(iD K. Arts, (D) J. H. Deijkers, (D) T. Faraz, (D) R. L. Puurunen, (D) W. M. M. (Erwin) Kessels, and (D) H. C. M. Knoops

\section{COLLECTIONS}

EP This paper was selected as an Editor's Pick
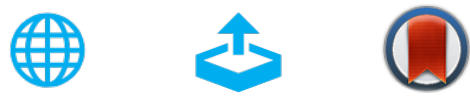

\section{ARTICLES YOU MAY BE INTERESTED IN}

Conformality in atomic layer deposition: Current status overview of analysis and modelling Applied Physics Reviews 6, 021302 (2019); https://doi.org/10.1063/1.5060967

Status and prospects of plasma-assisted atomic layer deposition

Journal of Vacuum Science \& Technology A 37, 030902 (2019); https://

doi.org/10.1116/1.5088582

Atomic layer deposition of silicon-based dielectrics for semiconductor manufacturing: Current status and future outlook

Journal of Vacuum Science \& Technology A 37, 060904 (2019); https://doi.org/10.1116/1.5113631

Challenge us.

What are your needs for periodic signal detection?

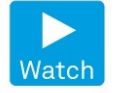

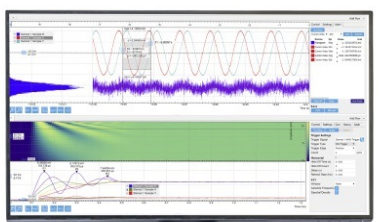

(1)
Zurich

- Instruments 


\title{
Evidence for low-energy ions influencing plasma-assisted atomic layer deposition of $\mathrm{SiO}_{2}$ : Impact on the growth per cycle and wet etch rate

Cite as: Appl. Phys. Lett. 117, 031602 (2020); doi: 10.1063/5.0015379

Submitted: 27 May 2020 - Accepted: 8 July 2020 .

Published Online: 22 July 2020
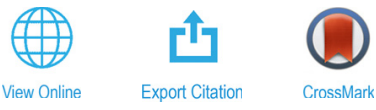

K. Arts, ${ }^{1}$ (D) J. H. Deijkers, ${ }^{1}$ (D) T. Faraz, ${ }^{1}$ (D) R. L. Puurunen, ${ }^{2}$ (D) W. M. M. (Erwin) Kessels, ${ }^{1, a)}$ (D) and H. C. M. Knoops ${ }^{1,3, a)}$ (D)

\begin{abstract}
AFFILIATIONS
${ }^{7}$ Eindhoven University of Technology, P.O. Box 513, 5600 MB Eindhoven, The Netherlands

${ }^{2}$ Aalto University School of Chemical Engineering, P.O. Box 16100, FI-00076 AALTO, Finland

${ }^{3}$ Oxford Instruments Plasma Technology, North End, Bristol BS49 4AP, United Kingdom
\end{abstract}

a) Authors to whom correspondence should be addressed:w.m.m.kessels@tue.hl and h.c.m.knoops@tue.nl

\begin{abstract}
This work provides evidence that plasma-assisted atomic layer deposition (ALD) of $\mathrm{SiO}_{2}$, a widely applied process and a cornerstone in selfaligned multiple patterning, is strongly influenced by ions even under mild plasma conditions with low-energy ions. In two complementary experimental approaches, the plasma ALD of $\mathrm{SiO}_{2}$ is investigated with and without the contribution of ions. The first set of experiments is based on microscopic cavity structures, where part of the growth surface is shielded from ions by a suspended membrane. It is observed that a lower growth per cycle (GPC) and a better material quality are obtained when an ion contribution is present. Without any ion contribution, a GPC of $1.45 \pm 0.15 \AA /$ cycle and a wet etch rate of $4 \pm 1 \mathrm{~nm} / \mathrm{s}$ (in $30: 1$ buffered HF) are obtained for a deposition temperature of $200^{\circ} \mathrm{C}$. With an ion contribution, these values decrease, where the magnitude of the decrease appears to be determined by the supplied ion energy dose. For extended ion doses, the GPC decreases to $0.85 \pm 0.05 \AA /$ cycle and the wet etch rate to $0.44 \pm 0.09 \mathrm{~nm} / \mathrm{s}$, approaching the value for a thermal oxide. The important role of ions is confirmed by the second experimental approach, which is based on ion-selective quartz crystal microbalance measurements. By these results, it is demonstrated that ions have a stronger impact on the plasma $\mathrm{ALD}$ of $\mathrm{SiO}_{2}$ than usually considered, providing essential insights for tailoring the film growth.
\end{abstract}

Published under license by AIP Publishing. https://doi.org/10.1063/5.0015379

Silicon oxide is an ubiquitous material that has many applications in nanoelectronics ${ }^{1,2}$ as well as in many other fields such as photovoltaics ${ }^{3}$ and photonics. ${ }^{4}$ Due to the ongoing downscaling of device features, atomic-scale processing techniques such as (plasmaassisted) atomic layer deposition (ALD) $)^{5,6}$ are becoming increasingly important, also for the synthesis of nm-thin $\mathrm{SiO}_{2}$ films. ${ }^{1,7}$ Among others, ${ }^{1}$ plasma ALD has become vital for the growth of $\mathrm{SiO}_{2}$ sidewall spacers in self-aligned multiple patterning, ${ }^{8,9}$ which now represents one of the largest segments of the global ALD market. ${ }^{7}$ A key benefit here is that the plasma ALD of $\mathrm{SiO}_{2}$ is relatively facile compared to thermally driven ALD and can provide high quality $\mathrm{SiO}_{2}$ even at low temperatures such as $50{ }^{\circ} \mathrm{C}$. ${ }^{10,1}$

As shown for several plasma ALD processes, energetic ions impinging on the surface during the plasma steps can play an important role. ${ }^{12}$ For example, Profijt et al. ${ }^{13}$ demonstrated that significantly increasing the kinetic energy of the ions through substrate biasing can induce a change in the growth per cycle (GPC) and material properties for $\mathrm{Al}_{2} \mathrm{O}_{3}, \mathrm{Co}_{3} \mathrm{O}_{4}$, and $\mathrm{TiO}_{2}$. In more comprehensive studies, Faraz et al. ${ }^{14}$ and Karwal et al. ${ }^{15,16}$ reported a large and often beneficial impact of substrate biasing and high ion energies (e.g., 100-200 eV) on the plasma ALD of titanium-, hafnium-, and silicon-based oxides and nitrides.

In this work, we provide conclusive evidence that even ions with low energies of $<20 \mathrm{eV}$ can significantly influence the plasma ALD of $\mathrm{SiO}_{2}$. This influence is seen for instance in the GPC and film quality, even under mild plasma conditions and when using a grounded substrate. Here, the film quality is assessed by the wet etch rate (WER) of the $\mathrm{SiO}_{2}$ film in a buffered hydrofluoric acid (BHF) solution. Moreover, the work demonstrates that the supplied ion energy dose $\mathrm{e}^{17}$ $\left(\mathrm{eV} \mathrm{nm}^{-2} \mathrm{cycle}^{-1}\right)$ is a key parameter, which can be used to tailor the film growth. These insights are valuable for current and future applications of the plasma ALD of $\mathrm{SiO}_{2}$ and expectedly also other materials.

The impact of ion exposure has been investigated by two independent experimental methods. In the first method, lateral-high-aspect-ratio 
(LHAR) trench structures were used, ${ }^{18,19}$ where only part of the growth area was exposed to ions. In the second method, film growth was monitored by a sensor with a quartz crystal microbalance (QCM), where the flux of ions to the quartz crystal could be controlled by varying the voltage applied to a grid embedded in the sensor. ${ }^{20}$ The main focus of this work is on the experiments using LHAR samples. In these experiments, it should be noted that ultraviolet (UV) and vacuum ultraviolet (VUV) radiation, which was present only at the ion-exposed surface, might also have affected the growth to some extent. Still, the experiments using the ion-selective QCM sensor, which has the same transmission of (V)UV radiation in the ion-blocking and ion-transmission mode, confirm that the observed trends were caused by ion exposure rather than by (V)UV.

Plasma ALD of $\mathrm{SiO}_{2}$ was carried out in a FlexAL ALD system of Oxford Instruments, which was equipped with a remote inductively coupled plasma (ICP) source operated at $13.56 \mathrm{MHz} .{ }^{21}$ Additionally, an external $13.56 \mathrm{MHz}$ power supply could be connected to the reactor table to apply a substrate bias. ${ }^{14,17}$ For all depositions, $\mathrm{SiH}_{2}\left(\mathrm{NEt}_{2}\right)_{2}$ was used as the precursor (with doses of $\sim 830 \mathrm{mTorr} \cdot \mathrm{s}$ per cycle) and $100 / 50 \mathrm{sccm} \mathrm{O} / \mathrm{Ar}$ plasma as the coreactant. Unless stated otherwise, $600 \mathrm{~W}$ ICP power, a grounded substrate, and a pressure of $50 \mathrm{mTorr}$ were used during the plasma steps, providing a relatively low ion flux and energy (i.e., $\sim 10^{13} \mathrm{~cm}^{-2} \mathrm{~s}^{-1}$ and $9 \pm 1 \mathrm{eV}$ average, see the supplementary material). No significant etching component (e.g., by sputtering) was present under these conditions (see the supplementary material). Plasma exposure times ranging from 3.8 up to $120 \mathrm{~s}$ per cycle were used to demonstrate the impact of the ion dose $\left(\mathrm{nm}^{-2} \mathrm{cycle}^{-1}\right)$. As reported in the supplementary material, similar trends are obtained within shorter plasma steps when supplying a higher ion energy and flux, for example by using a lower plasma pressure.

A schematic cross-sectional side view of the used LHAR structures (PillarHall ${ }^{\mathrm{TM}}$ generation 3 and 4 , developed by Puurunen and co-workers) $)^{18,19,22-28}$ is provided in Fig. 1(a), also illustrating film growth during plasma exposure. Using a network of Si pillars, a polysilicon membrane is suspended above a Si substrate with a nominal gap height of $500 \mathrm{~nm}$ to form a high-aspect-ratio horizontal trench. The anisotropic ions only impinge on the surface in the plasma-exposed region that is not covered by the membrane. In contrast, the reactive plasma radicals are supplied to the exposed and shielded region, as they can diffuse into the cavity up to aspect ratios as high as $\sim 900{ }^{23}$ After deposition, the membrane can be removed using an adhesive tape. Subsequently, in our experiments, the $\mathrm{SiO}_{2}$ thickness profile was measured by reflectometry (Filmetrics F40-UV with a StageBaseXY10-Auto-100 mm mapping stage) to retrieve the local GPC in terms of thickness per cycle as plotted in Fig. 1(b). The local WER, as plotted in Fig. 1(c), was determined by measuring the thickness profile before and after a $5 \mathrm{~s}$ etch in 30:1 BHF at room temperature with $\mathrm{NH}_{4} \mathrm{~F}$ as the buffer agent. The noise level in the reflectometry measurements is dependent on the local thickness of the film before and after etching. In addition to reflectometry, ex situ spectroscopic ellipsometry (SE) was performed on Si reference samples that were processed alongside the corresponding LHAR samples, to more accurately measure the GPC and WER obtained with ion exposure. To compare the impact of ions to the effect of temperature, depositions were carried out at table temperatures of 100,200 , and $300^{\circ} \mathrm{C}$, using 250,400 , and 250 ALD cycles per sample, respectively. Further experimental details are provided in the supplementary material.

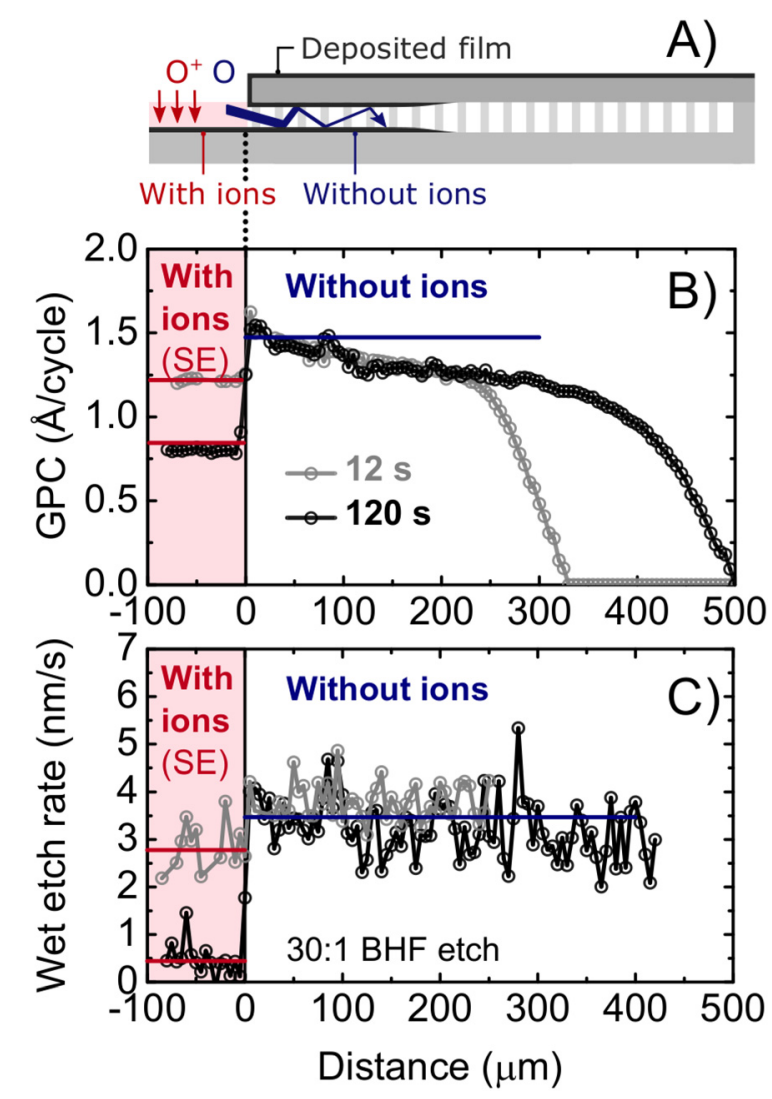

FIG. 1. LHAR cavity structures ${ }^{1}$

(a) with which the GPC (b) and wet etch rate (c) of $\mathrm{SiO}_{2}$ films grown with and without the ion contribution were investigated. The horizontal bars indicate the values obtained with (left) and without (right) ion exposure, which are based on the thickness profiles measured by reflectometry after removal of the membrane. The values obtained with ions (left) have been confirmed by SE. These results, obtained at a table temperature of $200^{\circ} \mathrm{C}$ using plasma steps of 12 and $120 \mathrm{~s}$, demonstrate that the GPC and WER decrease by the contribution of ions.

The data shown in Figs. 1(b) and 1(c) demonstrate that the GPC- and WER-values of the $\mathrm{SiO}_{2}$ grown with exposure to ions and neutrals (shaded area) are lower than those of the $\mathrm{SiO}_{2}$ grown by neutral species only. In the region without ion exposure, the local GPC gradually reduces with distance, while the material quality in terms of the WER remains similar with distance. In the ion-exposed region, the GPC and WER significantly decrease when using longer plasma steps, which is here exemplified by showing the results when using 12 and 120 s plasma exposure. In contrast, the GPC and WER in the region without ion exposure are not significantly influenced by the plasma exposure time (aside from a deeper film penetration into the cavity for a longer plasma exposure ${ }^{23}$ ). This indicates that the radical dose itself has a negligible effect on the $\mathrm{SiO}_{2}$ film thickness and quality when the plasma half-cycle is in saturation.

This experiment using LHAR samples has been repeated for a series of plasma exposure times, at various table temperatures. The results shown in Fig. 2 confirm that the plasma exposure time has a limited effect on the GPC and WER when the $\mathrm{SiO}_{2}$ is grown by neutral 

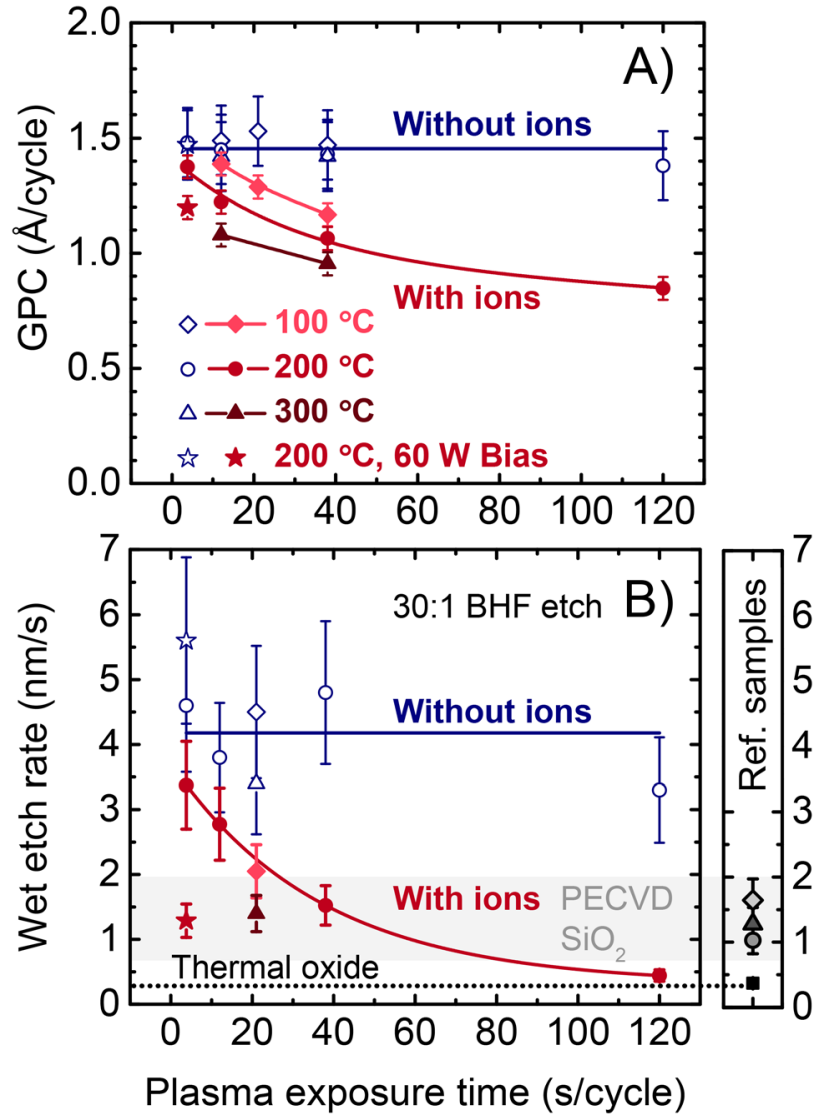

FIG. 2. GPC (a) and wet etch rate (b) of $\mathrm{SiO}_{2}$ films grown with and without ion contribution at table temperatures of 100,200 , and $300^{\circ} \mathrm{C}$, determined as shown in Fig. 1. With ion contribution, the GPC and WER decrease when using longer plasma exposures or by substrate biasing (here using $60 \mathrm{~W}$ bias power). For the deposition using plasma steps of $120 \mathrm{~s}$, the WER approached the value measured in this work for a thermal oxide (dotted line). The column at the right also provides WER values measured in this work for PECVD $\mathrm{SiO}_{2}$ grown at 100, 200, and $300^{\circ} \mathrm{C}$.

species only. In contrast, the GPC and WER are reduced with the ion contribution, where the reduction in GPC and WER is larger for longer plasma steps. The refractive index (at $633 \mathrm{~nm}$ ) remains approximately constant at $n \approx 1.45$ (see the supplementary material), indicating that the film density is relatively unaffected. As reference values, Fig. 2 also provides the WERs measured for $\mathrm{SiO}_{2}$ grown by plasma-enhanced chemical vapor deposition (PECVD) (see the supplementary material) and for a thermal oxide film. These values, obtained in this work under identical conditions, are similar to values reported in the literature (e.g., $1.4 \mathrm{~nm} / \mathrm{s}$ for $\mathrm{PECVD} \mathrm{SiO}_{2}$ and $0.28 \mathrm{~nm} / \mathrm{s}$ for a thermal oxide, extrapolated for 30:1 BHF from Williams et al. ${ }^{29}$ ). This comparison indicates that the film quality in terms of the WER is similar to $\mathrm{PECVD} \mathrm{SiO}_{2}$ for moderate ion doses and approaches the high quality of a thermal oxide for extended ion doses. Here, it should be noted that the ion energy also plays a role, as exemplified by the deposition using $60 \mathrm{~W}$ biasing (giving high ion energies of $\sim 120 \mathrm{eV}$ average).
Note that the GPC and WER are two very different parameters, where the GPC is influenced by the surface chemistry during film growth (e.g., $\mathrm{OH}$ surface coverage ${ }^{10}$ ) while the WER reflects the properties of the deposited film (e.g., impurity content ${ }^{30}$ ). Nevertheless, a high similarity between the impact of ions on the GPC and on the WER is observed. Both effects could be caused by surface dehydroxylation induced by the kinetic energy delivered by the impinging ions. A lower $\mathrm{OH}$ surface coverage can limit the amount of precursor adsorption per cycle and thereby lower the GPC, ${ }^{10}$ while dehydroxylation could also lower the $\mathrm{OH}$ impurity content in the film and reduce the WER. $^{30}$ Similarly, a higher deposition temperature can also induce dehydroxylation $^{31}$ and lower the GPC ${ }^{10}$ and WER. These factors make the effects of ion exposure and temperature somewhat interchangeable, as also observed in Fig. 2.

To confirm that ions are the species responsible for the observed effect, an additional experiment has been performed in the same reactor using a special ion-selective QCM sensor (Quantum probe of Impedans Ltd.). In this sensor, the QCM was embedded in a retarding field energy analyzer (RFEA). ${ }^{20}$ An RFEA is normally used to measure the energy distribution and flux of ions impinging on the substrate..$^{17,20,32,33}$ Here, as illustrated in Fig. 3(a), the RFEA grids were used to completely block $\left(e V_{D}>E_{i o n}\right)$ or partly ${ }^{20}$ transmit $\left(V_{D}=0\right)$ the flux of ions to the quartz crystal, where $V_{D}$ is the potential of the discriminator grid and $E_{i o n}$ the maximum ion energy. ${ }^{20} \mathrm{~A}$ representative result is shown in Fig. 3(b), where the absolute change in resonance frequency (which is proportional to the deposited mass) ${ }^{20,34}$ is plotted for $9 \mathrm{ALD}$ cycles of $\mathrm{SiO}_{2}$ with and without ion transmission. The slope of this signal represents the GPC in terms of mass per cycle, which here also reflects the thickness per cycle since the mass density is approximately unaffected (see the supplementary material). Under the used plasma conditions $\left(100^{\circ} \mathrm{C}, \sim 19\right.$ mTorr, $100 / 50$ $\mathrm{sccm} \mathrm{Ar} / \mathrm{O}_{2}, 600 \mathrm{~W}$ ICP power, $10 \mathrm{~W}$ bias power and $5 \mathrm{~s}$ plasma steps), the GPC with ion exposure was reduced to $78 \pm 7 \%$ of the value obtained without ion transmission. This is comparable to the reduction in GPC observed using the LHAR samples when using 38 s plasma exposure.

Both experimental approaches thus indicate a significant impact of ions on the plasma ALD of $\mathrm{SiO}_{2}$, yet the magnitude of this impact will depend on the reactor and plasma conditions used, i.e., on the flux and energy of the impinging ions, making it difficult to predict the growth behavior in general. A multitude of data corresponding to various experimental conditions is given in Fig. 4, which reveals that the magnitude of the influence of ions appears to be determined by the delivered ion energy dose. This parameter, calculated as ion flux $\times$ plasma exposure time $\times$ mean ion energy, ${ }^{17}$ was here estimated by RFEA measurements (see the supplementary material). The data are benchmarked against values obtained by Faraz et al. ${ }^{14}$ and by the ion-selective QCM data (the ratio $\mathrm{GPC}_{\text {With ions }} / \mathrm{GPC}_{\text {Without ions }}$ scaled assuming $1.45 \AA /$ cycle in the ion-blocking mode). Figure 4 can serve as a map to compare very different reactors and processing conditions. It also shows that the influence of ions on the plasma ALD of $\mathrm{SiO}_{2}$ is negligible when supplying an ion energy dose lower than $\sim 3 \mathrm{eV} \mathrm{nm}^{-2}$ per cycle. Conversely, the growth is significantly influenced when dosing for instance $100 \mathrm{eV} \mathrm{nm}^{-2}$ per cycle or higher. This effect will only be obtained at the surfaces undergoing ion impingement, e.g., the planar 

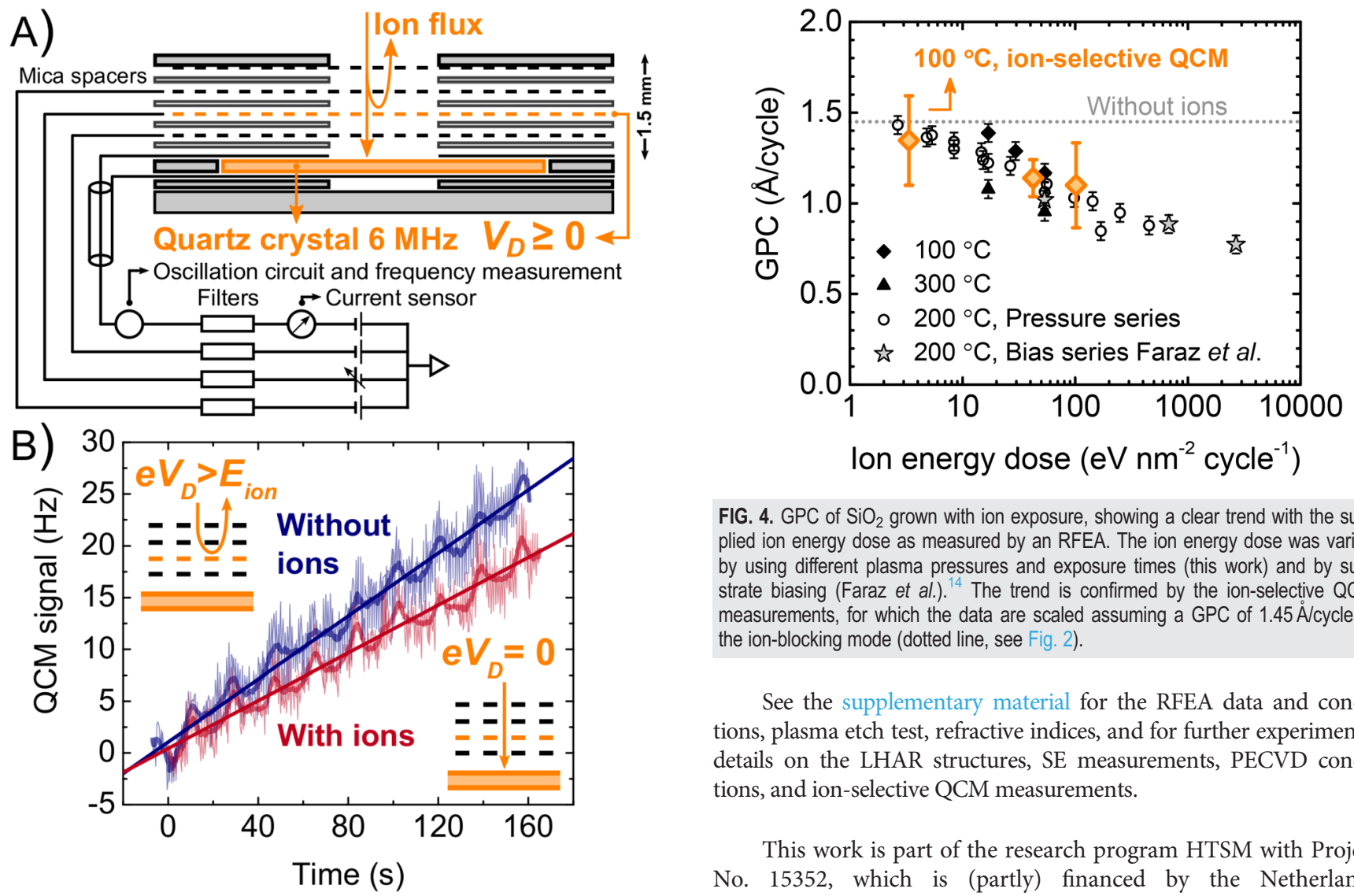

FIG. 4. GPC of $\mathrm{SiO}_{2}$ grown with ion exposure, showing a clear trend with the supplied ion energy dose as measured by an RFEA. The ion energy dose was varied by using different plasma pressures and exposure times (this work) and by substrate biasing (Faraz et al.). ${ }^{14}$ The trend is confirmed by the ion-selective QCM measurements, for which the data are scaled assuming a GPC of $1.45 \AA$ A/cycle in the ion-blocking mode (dotted line, see Fig. 2).

See the supplementary material for the RFEA data and conditions, plasma etch test, refractive indices, and for further experimental details on the LHAR structures, SE measurements, PECVD conditions, and ion-selective QCM measurements.

This work is part of the research program HTSM with Project No. 15352, which is (partly) financed by the Netherlands Organization for Scientific Research (NWO). The VTT Technical Research Centre of Finland Ltd. and Dr. M. Utriainen are acknowledged for supplying the PillarHall ${ }^{\mathrm{TM}}$ LHAR3 and LHAR4 conformality test structures. Impedans Ltd. and Dr. D. Gahan are acknowledged for providing the Quantum Single Sensor gridded quartz crystal microbalance and for the technical consultation. Furthermore, C. van Helvoirt, T. de Vries, P. Bax, and W. J. H. Berghuis are thanked for their technical support.

\section{DATA AVAILABILITY}

The data that supports the findings of this study are available within the article and its supplementary material.

\section{REFERENCES}

${ }^{1}$ R. A. Ovanesyan, E. A. Filatova, S. D. Elliott, D. M. Hausmann, D. C. Smith, and S. Agarwal, J. Vac. Sci. Technol., A 37, 060904 (2019).

${ }^{2}$ M. L. Green, E. P. Gusev, R. Degraeve, and E. L. Garfunkel, J. Appl. Phys. 90, 2057 (2001)

${ }^{3}$ A. G. Aberle, Prog. Photovoltaics Res. Appl. 8, 473 (2000).

${ }^{4}$ B. Jalali and S. Fathpour, J. Light. Technol. 24, 4600 (2006).

${ }^{5}$ S. M. George, Chem. Rev. 110, 111 (2010).

${ }^{6}$ H. B. Profijt, S. E. Potts, M. C. M. van de Sanden, and W. M. M. Kessels, J. Vac. Sci. Technol., A 29, 050801 (2011).

${ }^{7}$ H. C. M. Knoops, T. Faraz, K. Arts, and W. M. M. Kessels, J. Vac. Sci. Technol., A 37, 030902 (2019).

${ }^{8}$ J. Beynet, P. Wong, A. Miller, S. Locorotondo, D. Vangoidsenhoven, T.-H Yoon, M. Demand, H.-S. Park, T. Vandeweyer, H. Sprey, Y.-M. Yoo, and M. Maenhoudt, Proc. SPIE 7520, 75201J (2009). 
${ }^{9}$ A. Raley, S. Thibaut, N. Mohanty, K. Subhadeep, S. Nakamura, A. Ko, D. O’Meara, K. Tapily, S. Consiglio, and P. Biolsi, Proc. SPIE 9782, 97820F (2016).

${ }^{10} \mathrm{G}$. Dingemans, C. A. A. van Helvoirt, D. Pierreux, W. Keuning, and W. M. M. Kessels, J. Electrochem. Soc. 159, H277 (2012).

${ }^{11}$ M. Putkonen, M. Bosund, O. M. E. Ylivaara, R. L. Puurunen, L. Kilpi, H. Ronkainen, S. Sintonen, S. Ali, H. Lipsanen, X. Liu, E. Haimi, S. Hannula, T. Sajavaara, I. Buchanan, E. Karwacki, and M. Vähä-Nissi, Thin Solid Films 558, 93 (2014).

${ }^{12}$ C. Vallée, M. Bonvalot, S. Belahcen, T. Yeghoyan, M. Jaffal, R. Vallat, A. Chaker, G. Lefèvre, S. David, A. Bsiesy, N. Possémé, R. Gassilloud, and A. Granier, J. Vac. Sci. Technol., A 38, 033007 (2020).

${ }^{13}$ H. B. Profijt, M. C. M. van de Sanden, and W. M. M. Kessels, J. Vac. Sci. Technol., A 31, 01 A106 (2013).

${ }^{14}$ T. Faraz, H. C. M. Knoops, M. A. Verheijen, C. A. A. van Helvoirt, S. Karwal, A. Sharma, V. Beladiya, A. Szeghalmi, D. M. Hausmann, J. Henri, M. Creatore, and W. M. M. Kessels, ACS Appl. Mater. Interfaces 10, 13158 (2018).

${ }^{15}$ S. Karwal, M. A. Verheijen, B. L. Williams, T. Faraz, W. M. M. Kessels, and M. Creatore, J. Mater. Chem. C 6, 3917 (2018).

${ }^{16}$ S. Karwal, M. A. Verheijen, K. Arts, T. Faraz, W. M. M. (Erwin) Kessels, and M. Creatore, Plasma Chem. Plasma Process. 40, 697-712 (2020).

${ }^{17}$ T. Faraz, K. Arts, S. Karwal, H. C. M. Knoops, and W. M. M. Kessels, Plasma Sources Sci. Technol. 28, 024002 (2019).

${ }^{18}$ F. Gao, S. Arpiainen, and R. L. Puurunen, J. Vac. Sci. Technol., A 33, 010601 (2015).

${ }^{19}$ J. Yim, O. M. E. Ylivaara, M. Ylilammi, V. Korpelainen, E. Haimi, E. Verkama, M. Utriainen, and R. L. Puurunen, ChemRxiv (2020).

${ }^{20}$ S. Sharma, D. Gahan, P. Scullin, J. Doyle, J. Lennon, R. K. Vijayaraghavan, S. Daniels, and M. B. Hopkins, Rev. Sci. Instrum. 87, 043511 (2016).
${ }^{27}$ S. B. S. Heil, J. L. van Hemmen, C. J. Hodson, N. Singh, J. H. Klootwijk, F. Roozeboom, M. C. M. van de Sanden, and W. M. M. Kessels, J. Vac. Sci. Technol., A 25, 1357 (2007).

${ }^{22}$ K. Arts, V. Vandalon, R. L. Puurunen, M. Utriainen, F. Gao, W. M. M. Kessels, and H. C. M. Knoops, J. Vac. Sci. Technol., A 37, 030908 (2019).

${ }^{23}$ K. Arts, M. Utriainen, R. L. Puurunen, W. M. M. Kessels, and H. C. M. Knoops, J. Phys. Chem. C 123, 27030 (2019).

${ }^{24} \mathrm{M}$. Mattinen, J. Hämäläinen, F. Gao, P. Jalkanen, K. Mizohata, J. Räisänen, R. L. Puurunen, M. Ritala, and M. Leskelä, Langmuir 32, 10559 (2016).

${ }^{25}$ M. Ylilammi, O. M. E. Ylivaara, and R. L. Puurunen, J. Appl. Phys. 123, 205301 (2018).

${ }^{26}$ R. L. Puurunen and F. Gao, in 14th International Baltic Conference on Atomic Layer Deposition (2016), p. 20.

${ }^{27}$ A. M. Kia, N. Haufe, S. Esmaeili, C. Mart, M. Utriainen, R. L. Puurunen, and W. Weinreich, Nanomaterials $\mathbf{9}, 1035$ (2019).

${ }^{28}$ L. Souqui, H. Högberg, and H. Pedersen, Chem. Mater. 31, 5408 (2019).

${ }^{29}$ K. R. Williams, K. Gupta, and M. Wasilik, J. Microelectromech. Syst. 12, 761 (2003).

${ }^{30}$ V. Beladiya, M. Becker, T. Faraz, W. M. M. Kessels, P. Schenk, F. Otto, T. Fritz, M. Gruenewald, C. Helbing, K. D. Jandt, A. Tünnermann, M. Sierka, and A. Szeghalmi, Nanoscale 12, 2089 (2020).

${ }^{31}$ L. T. Zhuravlev, Colloids Surf., A 173, 1 (2000).

${ }^{32}$ D. Gahan, B. Dolinaj, C. Hayden, and M. B. Hopkins, Plasma Process. Polym. 6, S643 (2009).

${ }^{33}$ D. Gahan, S. Daniels, C. Hayden, P. Scullin, D. O'Sullivan, Y. T. Pei, and M. B. Hopkins, Plasma Sources Sci. Technol. 21, 024004 (2012).

${ }^{34}$ G. Sauerbrey, Z. Für. Phys. 155, 206 (1959). 